\title{
The impact of camera angles in learning videos on the perception of teaching excellence and emotional connectedness of students in the creative industries
}

\author{
Dennis A Olsen \\ University of West London, UK
}

\begin{abstract}
With the use of learning videos in higher education (HE) on the rise, and an increased importance assigned to the perception of teaching excellence by students in the United Kingdom (UK) and worldwide, this paper considers the impact of camera angles on students' perception of teaching excellence and students' emotional connectedness. Two focus groups comprising undergraduate students studying full time in subjects of the creative industries watched and discussed two videos with identical content (a presenter, presenting) but different camera angles - low-shot versus eye-level. The videos were provided as part of the course materials. The responses elicited in the focus groups suggest that an eye-level camera shot positively affects student perception of the presenter's credibility, goodwill and professionalism in learning videos. At the same time, findings call into question the suitability of presenterfocused learning videos altogether for the teaching of creative industries subjects in $\mathrm{HE}$, since students perceive that they lack sufficient presenter sparkle to enthuse, motivate and engage their audience.
\end{abstract}

Keywords: learning design, learning videos, camera angle, teaching excellence, creative industries

The Teaching Excellence and Student Outcome Framework in England, and in parts of Wales and Scotland, has put an increased emphasis on the importance of students' perception of teaching quality in higher education (HE) within the United Kingdom (UK) (Ashwin, 2017). This appears to have resulted in a disparity between disciplines within higher education institutions (HEls), with subjects associated with the creative industries, such as Design and Communication Studies, traditionally scoring - in the National Student Survey (NSS) - worse for teaching and learning than other disciplines (Burgess, Senior and Moores, 2018). Possible explanations for this range from the pedagogic culture in creative subjects to personality traits emphasised in the creative industries (Vaughan and Yorke, 2009). Irrespective of precisely what causes the disparity between disciplines, the reality is that the comparably lower score in terms of student perception of teaching and learning excellence has put additional pressure on educators within creative industries subjects to identify and apply novel teaching and learning approaches in order to boost levels of perception of teaching quality.

Generation Z, those born during or after 1995, currently makes up the majority of undergraduate students in HEls. This socio-demographic cohort exhibits a distinct desire for "educational opportunities that use technology and visual media" (Mohr and Mohr, 2017, p.92), thus 
furthering the continuous production of video content and its integration into HE as part of online, hybrid and collaborative learning environments (Greenberg and Zanetis, 2012; Johnson et al., 2014). From a student's point of view, the advantages associated with the use of video content are manifold and include - to name just a couple of examples - the "thinning of classroom walls" (Siemens, Gašević and Dawson, 2015, p.205) - that is, the decreasing importance of gathering in the same physical learning space - and the ability to revisit and review classroom material more independently.

Depending on their motivation and available time, students, for self-paced learning, employ different video-consumption strategies, ranging from rather structured approaches - such as watching videos from beginning to end in a single sitting - to zapping or skipping through video content (Boer, 2013). Notwithstanding these individual consumption approaches, Yousef, Chatti and Schroeder's (2014) meta-analysis of research, that considers video-based learning, concluded that the implementation of video content appears to have a positive impact on both the achievement of learning outcomes and learner satisfaction. Gorissen, van Bruggen and Jochems (2012) specify that video content, such as recorded lectures, appears to support students' learning, particularly during periods of exam preparation, when it becomes an effective tool for revision.

According to Hansch and colleagues (2015, p.4), "talking head videos" - that is, videos featuring one or more presenters talking at the camera - are among the most widely used audio-visual content in online learning settings. This presenter-centred content can facilitate a connection between the presenter and the audience, something that adds "nurturing value" (Koumi, 2006, p.46) to the educational environment, enhancing the student-staff relationship and improving student engagement and motivation (Guo, Kim and Rubin, 2014; Hansch et al., 2015). All of these aspects have been identified as playing a key role in students' evaluation of teaching quality (Su and Wood, 2012).

When it comes to the creation of video content, it appears to be the exception for presentercentred videos to be produced in a professional film studio environment. The production at brick-and-mortar educational institutions within the UK, as in most other countries, rarely falls within the responsibility of a centralised department and is often subsumed into the responsibilities of individuals or course teams without specialist equipment or training. The use of built-in cameras in laptops and desktop computers to record videos for educational purposes is, therefore, commonplace (Hansch et al., 2015; Berger, 2019). This, however, might have unintended consequences for student perception of teaching quality, for media research has repeatedly shown that the camera angle has a distinct impact on how audiences perceive video content and on how emotional connections between the audience and the people on screen are formed (Kuchenbuch, 2005; Schwender, 2006; Cao, 2013).

For their 2017 conference paper and subsequent journal article published in 2020, Ramlatchan and Watson investigated, inter alia, camera angles in learning videos, comparing the impact on instructor credibility and immediacy of high-angle and eye-level shots. The authors concluded that videos featuring an eye-level shot were significantly better received by students compared to those shot at a higher angle. The study did not include lower camera angles, which might 
seem surprising, as the established use of laptops and desktop computers for the recordings of learning videos is likely to result in such shots. Low-shot angles often trigger feelings of inferiority and powerlessness in audiences (Schwender, 2006). In the context of students' perception of teaching excellence, this might be particularly concerning, as the establishment of effective learning partnerships, with mutual respect between learners and teachers, is of paramount importance (Fried, 2001).

Given that teaching is a profoundly emotional practice (Liston and Garrison, 2004) and that it is essential for excellent teaching to have "a capacity to forge meaningful connectedness" (Su and Wood, 2012, p.151), it may be that certain camera angles in learning videos do improve or hinder staff connection with students. Connectedness refers to a 'felt concern' for students, which is apparent to learners and inspires and enthuses them, thus creating an environment in which learning is perceived as pleasurable (Barnett, 2007; Pring et al., 2009; Su and Wood, 2012). For the present study, therefore, successful connectedness would mean that learning videos actively contribute to the creation of such an environment during self-paced learning. This paper contributes to the continuing discussion by examining the impact of low-shot and eye-level camera angles in learning videos on students' perceptions of teaching excellence and emotional connectedness. Owing to the specific challenges arising from the introduction of the Teaching Excellence and Student Outcome Framework within the UK, the focus of this study is on the creative industries within HE.

In the context of the recent COVID-19 outbreak and the consequent accelerated shift towards online learning and teaching around the world, this research has become even more relevant. By April 2020, all HEls in the UK and in most parts of Europe have moved their teaching and learning efforts online, with a large number of academic staff, mostly unfamiliar with the specifics of distance learning, now exploring alternative modes of audio-visual communication with students to ensure effective teaching in the absence of a face-to-face teaching environment. During these times of heightened stress and anxiety for both students and academics (Lui, 2020; Venema, 2020), forging meaningful connectedness with students and keeping them engaged with their learning to create a sense of 'normality' seem of the utmost importance. The present paper has therefore a broad appeal to any educator who aims for effective and excellent teaching in HE via digital audio-visual channels. The strategic use of camera angles in both pre-recorded and live video communication might positively contribute to this objective.

\section{Research design}

Two short learning videos were produced, using two identical cameras for one low-shot version and one eye-level version of otherwise identical talking-head videos (figure 1). Each video lasted four minutes and fifty-five seconds and discussed the 'Unique Selling Proposition (USP)' concept; it included a selection of definitions, application strategies, advantages and limitations of the concept and also current industry examples. Whilst the eye-level camera was adjusted according to the presenter's real-life eye level, the height of the low shot was selected to replicate an in-built camera in a fourteen-inch laptop. 

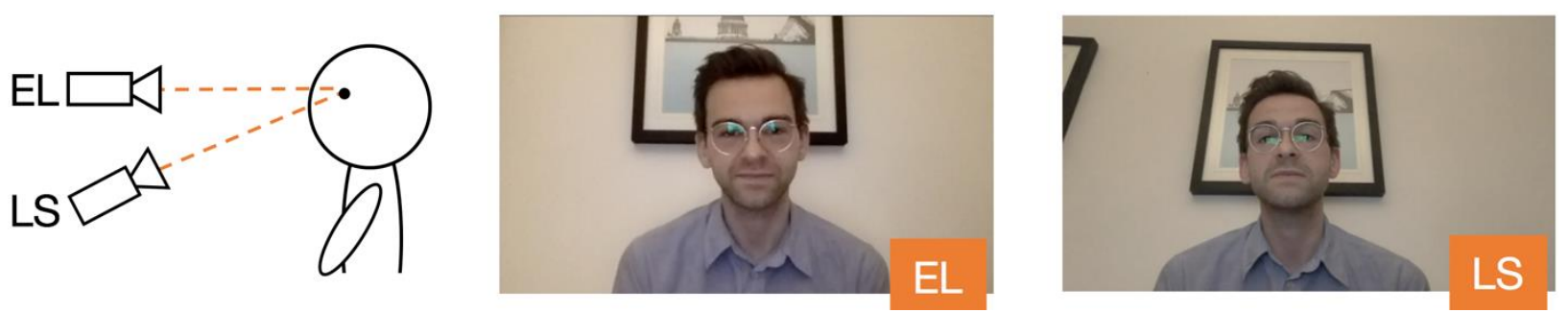

Figure 1: The investigation material consisted of two learning videos, identical except for the camera angle

After their creation, the two videos were shown to and discussed with two academic colleagues - from the London School of Film, Media and Design at the University of West London - who regularly produce learning videos as part of their own teaching practice. The purpose of this pretest was to confirm the appropriateness of the investigation material as a representation typical of a short learning video within the creative industries. Both colleagues independently verified the suitability of the investigation material, so that there were no changes to the videos for the final data collection.

Based on Schwender's (2006) investigation into audience perception and Reysen's (2005) Likability Scale, a question guide featuring thirteen open-ended questions was created, addressing aspects related to likeability, credibility, goodwill, communication immediacy and feeling of distance. Before the final data collection, a user question-comprehension pre-test (with two undergraduate students - not part of the final sample) took place and led to the minor rewording of just one question in order to improve its clarity. Subsequently, two focus groups with full-time, second-year undergraduate students (FHEQ level 5) from the University at West London were conducted on 20 March and 12 April 2019 at the University's St Mary's Road campus, London, UK. Participants were recruited via an open call in the London School of Film, Media and Design and were subsequently selected on the basis of comparable previous learning experiences - for example, level of study and previous exposure to learning videos as part of their studies. The first focus group comprised $N=6$ Advertising and Public Relations students (four female and two male), with a mean age of 21.7 years, $\sigma=2.1$. The second focus group comprised $N=8$ Media and Communications students (four female and four male), with a mean age of 21.3 years, $\sigma=1.3$. Both courses typically feature face-to-face learning environments, but occasionally incorporate learning videos in their virtual learning environment (VLE), enabling students to revisit and re-view content outside their weekly classes. 
Focus group: Ad and PR $(N=6)$

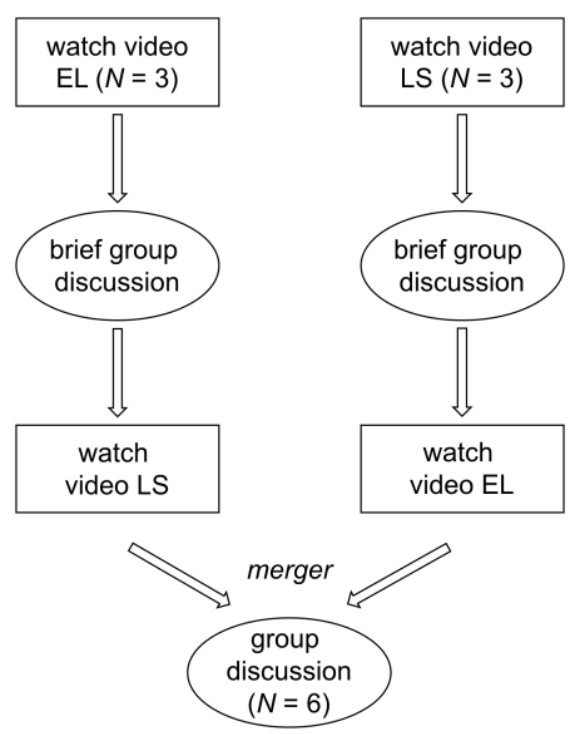

Focus group: Media and Communications $(N=8)$

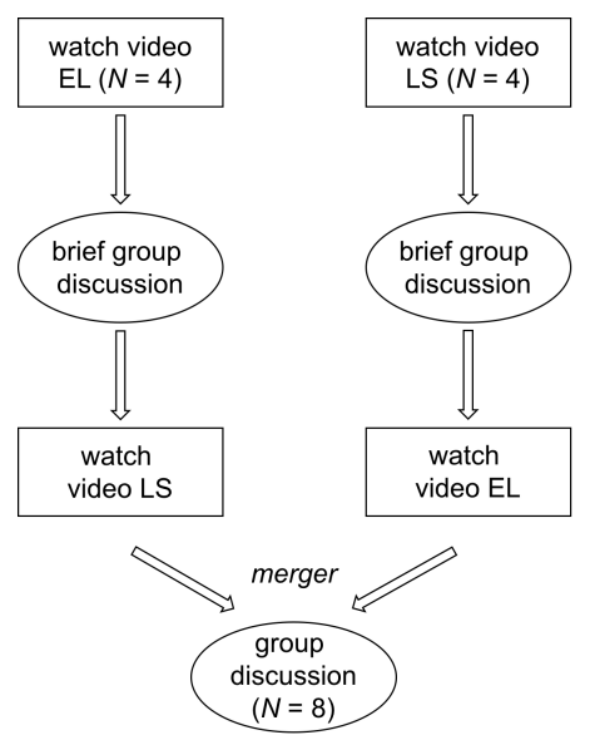

Figure 2: Flowcharts illustrating the two independent focus groups

As set out in figure 2, each of the two focus groups was initially split evenly but randomly into two sub-groups. Each sub-group was shown either the eye-level (EL) or the low-shot (LS) video first and then discussed it, before merging back into their two focus groups for extended discussions. The advantage of this staged approach was to gather initial, independent reactions to and opinions about each video, and thus camera angle, before moving to a more comparison-driven discussion. All parts of the focus groups were audio-recorded and the data subsequently analysed using qualitative content analysis (Mayring, 2014).

\section{Findings}

During the analysis of the qualitative data, three key themes emerged. The findings below are presented according to these key themes: (i) credibility and engagement; (ii) format and setting of the video; and (iii) quality, value for money and appropriateness of the learning artefact. To ensure anonymity, each participant was assigned a letter from A to N. The corresponding participant letter is indicated after each comment.

\section{Credibility and engagement}

In the eyes of the participants, a good lecturer, irrespective of whether $\mathrm{s} /$ he is in a face-to-face or online learning environment, must be a dual expert with both "knowledge about the industry [and] about how to teach" (E), while at the same time "not [being] patronising" (C), viz., interacting with students in a respectful manner. A sense of humour was also repeatedly pointed out as "very important to keep (...) engaged during a class" $(G)$ and the ability to build a good rapport with students.

Regarding the learning videos, the groups unanimously agreed that the low-angle shot "looked patronising" (I) and felt "more informal" (B) compared to the eye-level shot, which was perceived 
as "more professional" (A). Although the presenter's body position was pointed out as appearing more relaxed in the video featuring a low angle, this was not seen as a positive by students, but amplified the perception of unprofessionalism, with several participants in both groups characterising the video as "too relaxed" (F), "unserious" (A) and "sloppier" (L).

Despite being more critical overall of the low-angle shot, some students acknowledged that this reflected what they were familiar with from traditional face-to-face learning environments; however, participants' responses indicated that their reception of learning videos might be influenced less by their knowledge of classroom settings than by the consumption of other video content in their spare time. "Our generation watches a lot of YouTube and videos like that, it's always on [eye level], whereas in the class (...) the teacher stands in the front and we are sat (...) But this is different. We've learned so much with video content and it is more on our level; when it's a lower angle, it's not necessarily on our level" (C).

Neither of the camera angles was found to convey enthusiasm or motivate viewers to engage further with the content; both aspects, however, were pointed out as "definitely important" (M) for a good lecture. "If I was doing a course and I was watching those sort of videos every single week, l'd lose interest in the course" (L). "I'd click on it, watch it for ten seconds and then completely off-click it" (N). "You're facing a screen and you're watching someone talk directly at you. And obviously, you get that in real life experience when you go to a lecture, but that's more engaging than this" (B).

\section{Format and setting of the video}

Overall, participants from both groups seemed to question the use of presenters in learning videos, finding the experience "a bit unsettling, staring at someone who is staring back at you (...); I felt uncomfortable" (I). "Why do you need to show your face? Just show some visuals" $(F)$. It also seemed that there was an additional level of scrutiny of both the presenter and the content in learning videos compared to face-to-face learning environments. "It's the small things that bug me here (...) and in all videos that I see online, to be fair. In class with a lecturer, I'd probably not even notice" $(\mathrm{K})$. "In videos, these things are more obvious" (B). In terms of consumption situations, students agreed that the implementation of presenter-centred learning videos within a face-to-face learning environment was not desirable, but implementation as part of a VLE might be beneficial for their learning experience. "I would not want this as part of a lecture $(. .$.$) but maybe on Blackboard for when I am at home" (H)$. "This could be good for when I revise things between classes, but definitely not in class" $(A)$.

Inspiration for possible improvements was primarily drawn from social media, particularly YouTube tutorials. "YouTubers are better at this" (F). Participants unanimously agreed that what makes social media tutorials more successful than the presented learning videos was the fact that they were "more like a conversation" (D), involving interaction and movement on the presenter's part. Participants emphasise the importance of using visuals beyond the depiction of presenters, including "visual examples" and "subtitles" (A). All agreed that for them, it was crucial "to make [the video] more of an interesting visual (...), because we have short attention spans anyway" (B). 
Quality, value for money and appropriateness of the learning artefact

There seemed to be an expectation from students in both groups that the creative approach and production quality for learning videos in subjects of the creative industries should apply and reflect the skills that are purportedly being taught to the viewers. "It's kind of ironic that we're talking about a Unique Selling Point, when the video is completely un-unique and completely not very well designed" $(\mathrm{N})$. "Talking about something that is creative in the least creative way possible, l'd think I wasted my time and money" (E).

Several participants in one of the focus groups also questioned the use of videos as a suitable mode of delivery for content outside classroom settings overall, criticising the sequential nature of learning videos and the difficulties arising from navigating and searching for specific information. "Even though short, I don't like that I can't just jump in and out easily of a video (...) l'd always have to start again or search for the right stuff for ages" (G). "Maybe it would need to be broken down more? So, I can navigate (...); like maybe one-minute soundbites or something" (M). "I don't feel [a video] can replace reading a book. It is just way too difficult to go back and forth when I need to hear something again because I didn't get it the first time, or when I am looking for something specific" (K).

\section{Discussion and implications}

Between the two camera angles examined, the findings indicate that an eye-level shot might be more appropriate for presenter-centred learning videos. As in Ramlatchan and Watson (2017; 2020), the eye-level shot appears to affect positively the presenter's credibility and goodwill, in accordance with expectations derived from media theory (Schwender, 2006). An increase in perceived professionalism and decrease in the feeling of inferiority with an eye-level angle corresponds to Fried's (2001) call for a learning partnership and mutual respect between learners and teachers.

However, the findings call into question the use of presenter-centred learning videos as a format, with both videos perceived as lacking presenter enthusiasm, as well as being unable to motivate and engage, all of which were described by participants - and Su and Wood (2012) as key to students' perception of teaching excellence. Further, the perception that presenters talking into the camera was an eerie experience, irrespective of angles, indicates decreased approachability (a quality identified by Su and Wood (2012) as an important aspect, from a student's perspective, of a good lecture).

The desired emotional connectedness therefore might not be achieved by presenter-centred learning videos alone. A more visual-led approach, or at least enhancements that increase perceived quality, with an improved mechanism for navigation and use of interactive elements (Lui, 2020) could be a more effective way forward, chiming also with this age group's desire for "frequent educational opportunities that use technology and visual media" (Mohr and Mohr, 2017, p.92) and having positive impact upon students' levels of satisfaction (Yousef, Chatti and Schroeder, 2014). 
Nevertheless, this study, in combination with Ramlatchan and Watson's $(2017 ; 2020)$ insight, suggests to other HE practitioners that, when it comes to learning videos featuring presenters, an eye-level camera angle should be applied. Although likely not the default position of desktop computer or laptop cameras, the adjustment - that is, usually elevating the camera - might be worth the extra effort to facilitate effective teaching, particularly considering the increase in emphasis on students' perception of teaching quality in UK HE, owing to the Teaching Excellence and Student Outcome Framework and the current shift towards online teaching. A more professional approach to the production also appears to be advisable, in the light of the added level of scrutiny by students when interacting with video content outside classroom settings. Creative industries departments within HEls interested in supporting their teaching and learning experience with the help of learning videos might wish to consider additional support for academic staff involved in the production process.

\section{Future research}

The present study has underlined the importance of continuing research into learning videos and hopefully will inspire follow-up studies that expand on its findings. Future research might wish to build on the existing body of research in a meaningful way, by considering, inter alia, the following when recruiting participants:

Widening previous learning experiences. Students' level of study might influence their perception of learning videos. It could be that students who are exposed to talking-head videos early on during their studies regard these as the norm and thus view these videos more positively. Further exploration of whether student perception differs between those student populations more accustomed to distance learning and those primarily exposed to face-to-face learning environments seems also necessary for more generalisable conclusions to be drawn.

Including non-creative disciplines, such as law or economics, which often feature a more lecture-centred approach to teaching compared to the workshop-driven learning environments common in creative subjects. As a result, students' relative experience with classroom settings might have a bearing on the way they perceive presenter-centred videos.

Looking at different learning needs. The individual needs of students might also influence their perception of learning videos. For example, hearing-impaired students might find a presenter's facial cues helpful and thus would evaluate a talking-head video more positively. Students whose first language is not English might have a more pronounced appreciation of learning videos in general than would native speakers, as the medium allows for increased control such as pausing, replaying, etc. - of spoken teaching content.

Lastly, future research might also consider whether the negative perception resulting from an additional level of scrutiny by student audiences can be counteracted by a meaningful choice of presenter background - for example, via background blurring, or 'screened interior' (Rossi, 2020). 


\section{Conflict of Interest}

The author declares that there is no conflict of interest regarding the publication of this article.

\section{Reference list}

Ashwin, P. (2017) 'Making sense of the teaching excellence framework (TEF) results.' A Centre for Global Higher Education policy briefing by Paul Ashwin. Times Higher Education. Available at: https://www.timeshighereducation.com/news/teaching-excellence-framework-tef-results-2017 (Accessed: 1 April 2020).

Barnett, R. (2007) A Will to Learn: Being a Student in an Age of Uncertainty. Maidenhead, Berkshire: Open University Press. ISBN: 9780335223800

Boer, J.D. (2013) Learning from video: viewing behavior of students. Enchede: University of Groningen. ISBN: 9789461917683

Burgess, A., Senior, C. and Moores, E. (2018) 'A 10-year case study on the changing determinants of university student satisfaction in the UK.' PLOS ONE, 13(2), e0192976. Available at: https://doi.org/10.1371/journal.pone.0192976 (Accessed: 1 April 2020).

Cao, X. (2013) 'The Effects of Facial Close-Ups and Viewers' Sex on Empathy and Intentions to Help People in Need.' Mass Communication and Society, 16(2), 161-178. Available at: https://doi.org/10.1080/15205436.2012.683928 (Accessed: 1 April 2020).

Fried, R. (2001) The Passionate Teacher. Boston: Beacon Press. ISBN: 0807031437

Gorissen, P., van Bruggen, J. and Jochems, W. (2012) 'Students and recorded lectures: Survey on current use and demands for higher education.' Research in Learning Technology, 20(1063519), 297-311. Available at: https://doi.org/10.3402/rlt.v20i0.17299 (Accessed: 1 April 2020).

Greenberg, A.D. and Zanetis, J. (2012) The Impact of Broadcast and Streaming Video in Education. Available at: http://www.cisco.com/web/strategy/docs/education/ciscovideowp.pdf (Accessed: 1 April 2020).

Guo, P.J., Kim, J. and Rubin, R. (2014) 'How Video Production Affects Student Engagement: An Empirical Study of MOOC Videos.' ACM, 14, 41-50. Available at:

https://doi.org/10.1145/2556325.2566239 (Accessed: 1 April 2020).

Hansch, A., Newman, C., Hillers, L., Schildhauer, T., McConachie, K. and Schmidt. P. (2015) Video and Online Learning: Critical Reflections and Findings From the Field (discussion paper 
2015-02). Berlin: Alexander von Humboldt Institut für Internet und Gesellschaft. Available at: http://dx.doi.org/10.2139/ssrn.2577882 (Accessed: 1 April 2020).

Johnson, L., Adams Becker, S., Estrada, V. and Freeman, A. (2014) The NMC horizon report: 2014 higher education edition. Available at: http://cdn.nmc.org/media/2014-nmc-horizon-reporthe- EN-SC.pdf (Accessed: 1 April 2020).

Koumi, J. (2006) Designing video and multimedia for open and flexible learning. Oxon: Routledge. ISBN: 9780415383035

Kuchenbuch, T. (2005) Filmanalyse. Theorien. Methoden. Kritik. Vienna: Böhlau Verlag. ISBN: 9783825226480

Liston, D. and Garrison, J. (2004) Teaching, Learning, and Loving. New York: Routledge. ISBN: 9780415945158

Lui, K. (2020) ' "It's OK to feel anxious." How a professor in China faced coronavirus disruptions and fears.' Science. Available at: https://www.sciencemag.org/careers/2020/03/it-s-ok-feelanxious-how-professor-china-faced-coronavirus-disruptions-and-fears (Accessed: 1 April 2020).

Mayring, P. (2014) Qualitative Content Analysis. Theoretical Foundation, Basic Procedures and Software Solution. Klagenfurt: Beltz. Available at: https://nbn-resolving.org/urn:nbn:de:0168ssoar-395173 (Accessed: 1 April 2020).

Mohr, K. and Mohr, E. (2017) Understanding Generation Z Students to Promote a Contemporary Learning Environment. Journal on Empowering Teaching Excellence, 1(1), 8494. Available at: https://doi.org/10.15142/T3M05T (Accessed: 1 April 2020).

Pring, R. Hayward, G., Hodgson, A., Johnson, J., Keep, E., Oancea, A., Rees, G., Spours, K. and Wilde, S. (2009) Education for All. Oxon: Routledge. ISBN: 9780415547222

Ramlatchan, M. and Watson, G.S. (2017) 'Multimedia Video Resolution, Camera Angle, and the Impact on Instructor Credibility and Immediacy.' In: Simonson, M. and Seepersaud, D. (eds.), 40th Anual Proceeding. Selected Research and Development papers - Volume 1, 80-85. The Annual Convention of the Association for Educational Communications and Technology. Available at: https://www.tresystems.com/proceedings/documents/2017 jacksonville volume1.pdf (Accessed: 1 April 2020)

Ramlatchan, M. and Watson, G.S. (2020) 'Enhancing Instructor Credibility and Immediacy in the Design of Distance Learning Systems and Virtual Classroom Environments.' The Journal of Applied Instructional Design, 9(2). Available at:

https://edtechbooks.org/jaid 9 2/enhancing instructor (Accessed: 29 July 2020). 
Reysen, S. (2005) 'Construction of a new scale: The Reysen Likability Scale.' Social Behavior and Personality, 33(2), 201-208. Available at: https://doi.org/10.2224/sbp.2005.33.2.201

(Accessed: 1 April 2020).

Rossi, C. (2020) 'Screened Interiors: Researching Homes in Lockdown.' In: Midgelow V.L. (ed.), Doing Arts Research in a Pandemic. Location: The Culture Capital Exchange, 65-66. Available at: https://www.theculturecapitalexchange.co.uk/2020/06/02/doing-arts-research-in-a-pandemic2/ (Accessed: 29 July 2020).

Schwender, C. (2006) Medien und Emotionen. Evolutionspsychologische Bausteine einer Medientheorie. Wiesbaden: Deutscher Universitätsverlag. ISBN: 978-3835060456

Siemens, G., Gašević, D. and Dawson, S. (2015) Preparing for the digital university: a review of the history and current state of distance, blended, and online learning. Edinburgh: MOOC Research Initiative. Available at: https://www.research.ed.ac.uk/portal/en/publications/preparingfor-the-digital-university(585b85b0-74b2-4e31-8697-255c649183a6).html (Accessed: 1 April 2020).

Su, F. and Wood, M. (2012) 'What makes a good university lecturer? Students' perceptions on teaching excellence.' Journal of Applied Research in Higher Education, 4(2), 142-155. Available at: https://doi.org/10.1108/17581181211273110 (Accessed: 1 April 2020).

Vaughan, D. and Yorke, D. (2009) 'I can't believe it's not better': The Paradox of NSS scores for Art \& Design. Available at: https://www.advance-he.ac.uk/knowledge-hub/i-cant-believe-its-notbetter-paradox-nss-scores-art-design?PageSpeed=noscript (Accessed: 1 April 2020).

Venema, V. (2020) 'Coronavirus: “It's just anxiety, anxiety, anxiety”.' BBC News Stories. Available at: https://www.bbc.co.uk/news/stories-52110460 (Accessed: 1 April 2020).

Yousef, A., Chatti, M. and Schroeder, U. (2014) 'Video-Based Learning: A Critical Analysis of The Research Published in 2003-2013 and Future Visions.' In: eLmL 2014, The Sixth International Conference on Mobile, Hybrid and On-line Learning 112-119. Available at: http://www.thinkmind.org/download.php?articleid=elml 201453050050 (Accessed: 1 April 2020). 